\title{
Effects of anesthesia type on short-term postoperative cognitive function in obstetric patients following cesarean section
}

\author{
Celalettin Altun ${ }^{1}$, Hale Borazan', Osman Şahin ${ }^{1}$, Kazım Gezginç$^{2}$ \\ ${ }^{1}$ Department of Anesthesiology and Reanimation, Necmettin Erbakan University Faculty of Meram Medicine, Konya, Turkey \\ ${ }^{2}$ Department of Obstetrics and Gynaecology, Necmettin Erbakan University Faculty of Meram Medicine, Konya, Turkey
}

\begin{abstract}
Objective: We aimed to compare the effects of general and spinal anesthesia on cognitive functions in pregnant patients undergoing elective cesarean section.

Material and Methods: Seventy-five American Society of Anesthesiology (ASA) I pregnant patients aged 18-40 years who were scheduled to undergo elective cesarean section were divided into three groups. Group sevoflurane (Group S) and Group desflurane (Group D) were administered general anesthesia, whereas Group regional (Group R) was administered spinal anesthesia. Hemodynamic variables, bispectral index, oxygen saturation were measured at baseline, after induction, spinal injection, and during the surgery. Extubation and eye opening time and Aldrete scores were recorded. Mini-mental state examination, Trieger dot test, and clock drawing test were performed one day before the surgery and repeated at the $1^{\text {st }}, 3^{\text {rd }}$ and $24^{\text {th }} \mathrm{h}$ postoperatively.

Results: There was no statistically significant difference among the groups in terms of demographic data and duration of surgery ( $p>0.05$ ). Durations of anesthesia for Group S, Group R, and Group D were significantly different $(\mathrm{p}<0.05)$. Duration of anesthesia for Group R was significantly longer than for Groups $\mathrm{S}$ and $\mathrm{D}(\mathrm{p}<0.0001)$. Aldrete recovery scores and total remifentanil consumption were significantly higher in Group D than in Group S ( $<0.05)$. Extubation and eye opening times were significantly shorter in Group D than in Group S $(\mathrm{p}<0.01)$. According to TDT, statistical significance was found among Group S, Group R, and Group D at the 3rd and 24th h postoperatively $(\mathrm{p}<0.05)$, and there was a statistically high significant difference in Groups $\mathrm{S}$ and $\mathrm{R}(\mathrm{p}<0.0001)$.

Conclusion: We concluded that general anesthesia with sevoflurane or desflurane and spinal anesthesia had no effects on cognitive functions in patients undergoing cesarean operation. (J Turk Ger Gynecol Assoc 2015; 16: 219-25)

Keywords: Sevoflurane, desflurane, general anesthesia, spinal anesthesia, cognitive function, cesarean section
\end{abstract}

Received: 16 April, $2015 \quad$ Accepted: 15 August, $2015 \quad$ Available Online Date: 02 November, 2015

\section{Introduction}

Postoperative cognitive dysfunction (POCD), a common brain complication following surgery and anesthesia, is characterized by the impairment of recent memory, concentration, language comprehension, and social integration. While the diagnosis of delirium requires detection of symptoms, the diagnosis of POCD requires preoperative neuropsychological testing (baseline) and a determination that defines how much of a decline is called cognitive dysfunction (1). POCD may occur after any type of surgery and at any age but is most often associated with cardiac surgery and in patients over the age of 60 years $(1,2)$.

Although anesthetics have effects on organs and systems, their main impact is on the central nervous system, and this situation leads to affect the cognitive functions which is an upper brain activity in varying degrees and periods after general anesthesia. Rapid recovery of patients who have been under general anesthesia and their returning to their pre-anesthesia condition mentally are major goals for anesthetists $(3,4)$. It takes time for psychomotor functions to return to the preoperative levels after the anesthesia is ended (5). It has been demonstrated that after being exposed to anesthetics, psychomotor and cognitive functions are impaired for 10-12 h. This impairment can last for 1-2 days, and these symptoms may even occur with the smallest anesthetic administration $(6,7)$. Furthermore, in the post-anesthetics period, memory is more affected in young patients, whereas the mental organizations are more affected in elderly patients $(3,8)$.

The choice of an anesthetic method for cesarean operations depends on the reason for the procedure, its degree of urgency, and on the preference of both the patient and anesthetist. There is no anesthetic method ideal for cesarean operations. The anesthetist must choose a method that they believe is the safest and most comfortable for the mother, has the least depressant effect on the newborn, and ensures optimal operat- 
ing conditions for the surgery. Although there are studies that suggest that general anesthesia and insufficient postoperative pain control play a role in the development of early POCD (9, $10)$, there are other studies asserting that the type of anesthesia (general or regional) does not affect the formation and development of POCD (11).

A study focusing on the comparison of POCD after cesarean operations using spinal anesthesia and general anesthesia has not been found in literature. Therefore, this study aims to compare the effect of sevoflurane, desflurane, and spinal anesthesia on intraoperative hemodynamics, recovery, and early cognitive functions in patients who will undergo elective cesarean operation.

\section{Material and Methods}

Following the approval of the Faculty Ethics Committee (No: Jan 2013/311), 75 pregnant women who will undergo elective cesarean operation, are aged $\geq 18$ years, have ASA I physical status, are in the full term, and whose consents were taken were included in the study. Emergency patients, multiple and pre-term pregnancies, growth retardations, patients known to have congenital malformation, patients known to have neurological or psychiatric diseases affecting the central nervous system (CNS) and cognitive functions, patients who were taking medications affecting CNS, patients with malnutrition and dehydration, patients known to have low levels of vitamin B12 and folic acid, patients with alcohol or any substance addictions, and patients aged $>40$ years were excluded from the study.

Patients included in the study were divided in three random groups: as undergoing general anesthesia with sevoflurane (Group $\mathrm{S}, \mathrm{n}=25$ ), undergoing general anesthesia with desflurane (Group $\mathrm{D}, \mathrm{n}=25$ ), and undergoing regional anesthesia via spinal injection (Group $\mathrm{R}, \mathrm{n}=25$ ). It was ensured that from arrival at the operating room to the end of the procedure, all pregnant women lay on their left side at $15^{\circ}$. To determine the levels of cognitive functions of patients, the Trieger dot test (TDT), mini-mental state examination (MMSE), and clock drawing test (CDT) have been performed one day before the procedure. In patients taken to the operating room, peripheral vascular access was established with the 18 gauge cannula, and $500 \mathrm{cc}$ of $0.9 \% \mathrm{NaCl}$ solution was administered until anesthesia induction. Electrocardiogram, peripheral oxygen saturation $\left(\mathrm{SpO}_{2}\right)$, and non-invasive arterial pressure monetarization (Datex-Ohmeda S/5 Anesthesia Delivery Unit, Bromma, Sweden) were performed, and none of the patients were pre-medicated.

Systolic artery pressure (SAP), diastolic artery pressure (DAP), mean arterial pressure (MAP), $\mathrm{SpO}_{2}$, heart rate (HR), and bispectral index (BIS) (Drager infinity kapa, Drager medical systems Inc., Denvers, USA) levels were monitored, and the measured values were recorded as baseline values. In the general anesthesia groups, these measurements were recorded after general anesthesia induction, after intubation, in every $5 \mathrm{~min}$ from the beginning and the end of the procedure, during extubation, and 5 min after extubation. In general anesthesia groups, in addition to these measurements, the measurements of intraoperative end tidal sevo/des \% with 5-min intervals, mean end tidal sevo/ des $\%$ at the end of the case, and total consumed remifentanil
(Ultiva flk ${ }^{\circledR}$, GlaxoSmithKline, İstanbul, Turkey) dosage and end tidal carbon dioxide measures were also recorded.

In all three groups, patients were administered pre-oxygenation for 3-5 min with $100 \%$ oxygen. In Groups S and D, for anesthesia induction, $0.5 \mu \mathrm{g} / \mathrm{kg}$ remifentanil was administered as a bolus for $30 \mathrm{~s}$, and then $0.2 \mu \mathrm{g} / \mathrm{kg} / \mathrm{m}$ remifentanil infusion was continued and induction was completed with $4 \mathrm{mg} / \mathrm{kg}$ thiopental (Pental $\mathrm{flk}^{\circledR}$, İE Ulagay İlaç, İstanbul, Turkey) and $1 \mathrm{mg} / \mathrm{kg}$ succinylcholine (Lysthenon amp ${ }^{\circledR}$, Fako İlaç, İstanbul, Turkey). For maintenance of anesthesia, Group $\mathrm{S}$ was administered 0.5 MAC sevoflurane, $50 \% \mathrm{O}_{2}+50 \% \mathrm{~N}_{2} \mathrm{O}$; and Group D was administered 0.5 MAC desflurane, $50 \% \mathrm{O}_{2}+50 \% \mathrm{~N}_{2} \mathrm{O}$. Cricoid pressure was applied to patients along with anesthesia induction. After maintaining relaxation, endotracheal intubation was performed, and cricoid pressure was discontinued by inflating the cuff. Patients were ventilated with a tidal volume of $8-10 \mathrm{~mL} / \mathrm{kg}$ and respiratory rate of $10-12 / \mathrm{min}$ to achieve an $\mathrm{EtCO}_{2}$ of $30-34 \mathrm{mmHg}$. $10-12 / \mathrm{m}$ respiration frequency to provide end tidal $\mathrm{CO}_{2} 30-34$ mmHg. A $20 \%$ increase in MAP and/or $>90$ pulse/m HR or $>60$ BIS levels of the patient after the baby was born was considered as light anesthesia, and remifentanil dosage was increased by $25 \%$. When the increase in remifentanil dosage was insufficient, the dosage of general anesthetic agent was increased. A 20\% decrease in the MAP value and/or $<50$ pulse/m HR and/or $<40$ BIS value was considered as deep anesthesia, and remifentanil dosage was decreased by $25 \%$. When the decrease in remifentanil dosage was insufficient, the dosage of general anesthetic agent was decreased. Neuromuscular transmission was monitored in patients. Patients were administered succinylcholine as a neuromuscular blocking agent, and neuromuscular transmission (NMT) (Infinity Trident ${ }^{\circledR}$, Drager, Germany) measures were obtained with a single-twitch method. When the twitch had recovered to 0.20 of its control value $0.1 \mathrm{mg} / \mathrm{kg}$ atracurium (Dematrac ${ }^{\circledR}$, Dem İlaç, İstanbul, Turkey) was administered. During the procedure, anesthetic and analgesic requirements were adjusted to maintain MAP and HR values at a $\pm 20 \%$ limit of the baseline value, and the BIS value between 40 and 60 . After the baby was born, 10 iu of oxytocin were slowly intravenously administered. Further, 10-20 iu of oxytocin were added to 1000 $\mathrm{mL}$ isotonic. General anesthetic agent was discontinued at the start of skin closure while remifentanil infusion was terminated at the completion of fascia closure. To provide postoperative analgesia, $2 \mathrm{mg} / \mathrm{kg}$ tramadole $\left(\right.$ Contramal ${ }^{\circledR}$, Abdi İbrahim İlaç, İstanbul, Turkey) and $20 \mathrm{mg}$ tenoxicam (Oksamen ${ }^{\circledR}$, Mustafa Nevzat İlaç, İstanbul, Turkey) were intravenously administered after the baby was born. At the end of the procedure, when the TOF ratio (ratio of forth twitch to the first) returned to at least 0.9 , the patients were extubated. Then the patients were followed in the postanesthesia care unit. In groups undergoing general anesthesia, Aldrete recovery scores were recorded in the $2^{\text {nd }}$ and $5^{\text {th }}$ minutes. In the groups undergoing general anesthesia, the duration of anesthesia was recorded as the time between the beginning of anesthesia induction and extubation, and extubation time was recorded as the period between termination of all anesthetic medicine and the time when extubation was possible. For individuals in Groups $\mathrm{S}$ and $\mathrm{D}$, in addition to extubation times, spontaneous eye opening times at the end of 
the procedure were also recorded. The duration of the surgery was recorded as the period between the first skin incision and last skin suture.

In the spinal anesthesia group, Group R, the levels of SAP, DAP, MAP, $\mathrm{SpO}_{2}, \mathrm{HR}$, and BIS for all pregnant women were monitored, and the measured values were recorded as baseline. In Group R, these measurements were recorded after spinal injection with 5-min intervals between the beginning and end of the procedure. Skin disinfection for pregnant women in Group $\mathrm{R}$ was performed in the sitting position with the antiseptic solution, and the subarachnoid space was penetrated between the L3-L4 or L4-L5 gap with a $25 \mathrm{G}$ atraumatic spinal needle from midline. After free, clean cerebrospinal fluid flow was observed, 10-12 mg bupivacaine (10 mg for patients shorter than $165 \mathrm{~cm}$ and $12 \mathrm{mg}$ for patients taller than $165 \mathrm{~cm}$ ) was administered for 10-15 s. The level of sensorial blockade was determined with the pinprick test, while the level of motor blockade was determined with the Bromage scale. The interval between starting of the intrathecal injection and the time when no pain was felt in the T4 dermatome was regarded as the sensorial blockade starting time. The interval between the end of intrathecal injection and the time when Bromage was 2-3 was regarded as the motor blockade starting time. The maximum level of sensorial blockade, time when sensorial blockade reached the T4 dermatome level (starting time of sensorial blockade), motor blockade starting time, motor blockade at 5 min (Bromage score), and regression time of sensorial blockade to the T10 dermatome level were recorded. Surgery was allowed when sensorial blockade reached the T5-T4 dermatome level. In the spinal anesthesia group, 5-10 mg ephedrine was intravenously administered in case significant hypotension developed (initial SAP below 20-30\%). In case of bradycardia (45 or less pulse per minute) atropine was intravenously administered, and patients who were administered with atropine were excluded from the study. After the baby was born, 10 units of oxytocin were slowly intravenously administered; 10-20 units of oxytocin were added to $1000 \mathrm{~mL}$ isotonic. The Duration of surgery was recorded as the period between the first skin incision and the last skin suture. For individuals in Group R, the duration of anesthesia was recorded as the time between the beginning of spinal anesthesia and the last skin suture. Patients in Group $\mathrm{R}$ were also administered $2 \mathrm{mg} / \mathrm{kg}$ tramadole, and $20 \mathrm{mg}$ tenoxicam was intravenously administered at the end of the surgery.

In case the visual analogue scale (VAS) value of individuals in all the three groups was 4 or above, additional analgesia with 1 $\mathrm{mg} / \mathrm{kg}$ tramadole was intravenously administered. Thus, it was aimed to have the VAS values of 4 or less for patients. Because of the possibility of postoperative pain affecting cognitive functions, patients with postoperative $1^{\text {st }}$ and $3^{\text {rd }}$ hour VAS values over 4 , despite the administration of additional analgesia, were excluded from the study.

The evaluation of the newborn was performed by a pediatrician with Apgar scores in the $1^{\text {st }}$ and $5^{\text {th }}$ minutes after the birth. In all the three groups, the starting of anesthesia-time of birth, uterus incision-time of birth and whether the newborn required resuscitation or not (ambu or intubation) were recorded.

To evaluate cognitive functions of individuals in all the three groups, MMSE, TDT, and CDT tests were performed again in the postoperative $1^{\text {st }}, 3^{\text {rd }}$, and $24^{\text {th }} \mathrm{h}$. Patients were monitored for adverse effects, such as nausea and vomiting, desaturation, and hypotension.

\section{Statistical analysis}

We accepted a type I error of 0.05 and type II error of 0.80 for detecting a true difference. A 0.5 or greater difference in the independent variables was considered clinically significant. An estimate of standard deviation in independent variables was 1 . Therefore, we calculated that a minimum of 23 patients were required in each group to obtain 5\% type 1 error and an $80 \%$ power of detecting a difference of 0.5 or more. For each group, 25 patients were included to compensate for the possible dropouts. The power calculation was performed with nQuery Advisor Version 7.0 (Statistical Solutions, Saugus, MA, USA).

In this study, data obtained were evaluated with SPSS 20.0 packet program. Frequencies and percentile distributions of data were stated. According to the normality test, differences among groups were analyzed, and for comparison of two groups Mann-Whitney U Test was used for variables that were not normally distributed.. For comparisons of three groups Bonferronicorrected Kruskal-Wallis $\mathrm{H}$ test was used for variables that were not normally distributed; $\mathrm{p}<0.05$ was accepted as statistically significant.

\section{Results}

Seventy-five pregnant patients who planned to undergo elective cesarean operation under general and spinal anesthesia and who fell into the ASA I risk group were included in the study. Height, weight, and the durations of surgery do not demonstrate a significant difference in terms of anesthesia methods ( $p>0.05$ ) (Table 1). When the durations of anesthesia between the groups were analyzed, the duration of anesthesia for patients in Group R was found to be significantly longer than that in Group D $(\mathrm{p}<0.05)$ (Table 1).

When the HR values of groups S, R, and D were compared, $\mathrm{HR}$ in $10^{\text {th }}, 15^{\text {th }}, 20^{\text {th }}$, and $25^{\text {th }}$ minutes for patients in Group $\mathrm{R}$ was found to be significantly higher than that those in Group $S$ $(\mathrm{p}<0.05)$, HR in $20^{\text {th }}$ and $25^{\text {th }}$ minutes for patients in Group R was found to be significantly higher than that of patients in Group D $(p<0.05)$, and extubation HR for patients in Group D was found to be significantly higher than that of patients in Group $S$ $(\mathrm{p}<0.05)$ (Figure 1).

In terms of MAP, post-induction MAP in the $5^{\text {th }}, 25^{\text {th }}$, and $30^{\text {th }}$ minutes of patients in Group D was found to be significantly higher than that of patients in Group R, and MAP in $5^{\text {th }}$ minute of patients in Group $\mathrm{S}$ was found to be significantly higher than that of patients in Group R $(p<0.05)$. There were no statistically significant difference among the groups in terms of the baseline; post-intubation; $10^{\text {th }}, 15^{\text {th }}$, and $20^{\text {th }}$ minute; and extubation and post-extubation $5^{\text {th }}$-minute MAP values $(\mathrm{p}>0.05)$ (Figure 2$)$. Post-induction $5^{\text {th }}, 10^{\text {th }}, 15^{\text {th }}, 20^{\text {th }}, 25^{\text {th }}$, and $30^{\text {th }}$-minute BIS values of patients in Group $\mathrm{R}$ were found to be significantly higher than those in the other two groups $(\mathrm{p}<0.05)$. Extubation and postextubation $5^{\text {th }}$-minute BIS values of patients in Group D were found to be significantly higher than those in Group $S(p<0.05)$. 
Table 1. Patient characteristics, intraoperative and postoperative variables

\begin{tabular}{|c|c|c|c|}
\hline Groups & $\begin{array}{c}\text { Group S } \\
(n=25)\end{array}$ & $\begin{array}{c}\text { Group D } \\
(n=25)\end{array}$ & $\begin{array}{c}\text { Group R } \\
(n=25)\end{array}$ \\
\hline Age (year) & $29.12 \pm 6.36$ & $28.44 \pm 6.38$ & $26.56 \pm 4.65$ \\
\hline Weight (kg) & $73.20 \pm 8.35$ & $75.48 \pm 9.07$ & $72.44 \pm 8.31$ \\
\hline Height $(\mathrm{cm})$ & $162.8 \pm 4.96$ & $161.47 \pm 4.85$ & $161.84 \pm 3.91$ \\
\hline $\begin{array}{l}\text { Gestational Age } \\
\text { (week) }\end{array}$ & $37.56 \pm 0.87$ & $37.44 \pm 0.87$ & $37.24 \pm 1.23$ \\
\hline $\begin{array}{l}\text { Duration of } \\
\text { anesthesia (min) }\end{array}$ & $32.68 \pm 2.98$ & $31.52 \pm 2.63$ & $36.04 \pm 6.92^{*}$ \\
\hline $\begin{array}{l}\text { Duration of surgery } \\
\text { (min) }\end{array}$ & $29.80 \pm 2.58$ & $28.52 \pm 2.87$ & $30.48 \pm 4.39$ \\
\hline $\begin{array}{l}\text { Remifentanil } \\
\text { Consumption }(\mu \mathrm{g})\end{array}$ & $371.44 \pm 58.62$ & $461.20 \pm 79.33$ & - \\
\hline $\begin{array}{l}\text { Extubation time } \\
\text { (min) }\end{array}$ & $6.84 \pm 1.43^{\alpha}$ & $2.64 \pm 1.63$ & - \\
\hline $\begin{array}{l}\text { Eye opening time } \\
\text { (min) }\end{array}$ & $8.08 \pm 1.71^{\beta}$ & $3.76 \pm 1.74$ & - \\
\hline $\begin{array}{l}\text { Aldrete Recovery } \\
\text { Score } 2^{\text {nd }} \text { min }\end{array}$ & $7.64 \pm 0.49^{\#}$ & $8.16 \pm 0.47$ & - \\
\hline $\begin{array}{l}\text { Aldrete Recovery } \\
\text { Score } 5^{\text {th }} \text { min }\end{array}$ & $8.96 \pm 0.54^{€}$ & $9.36 \pm 0.70$ & - \\
\hline \multicolumn{4}{|c|}{$\begin{array}{l}\text { Values are shown as Mean } \pm \text { SD. } \\
" p=0.047 \text { (Comparison between Group R and Group D) } \\
{ }^{\alpha} \mathrm{p}<0.001 \text { (Comparison between Group S and Group D) } \\
{ }^{\beta} \mathrm{p}<0.001 \text { (Comparison between Group S and Group D) } \\
{ }^{\#} \mathrm{p}=0.01 \text { (Comparison between Group } S \text { and Group D) } \\
{ }^{\epsilon} \mathrm{p}=0.022 \text { (Comparison between Group } S \text { and Group D) }\end{array}$} \\
\hline
\end{tabular}

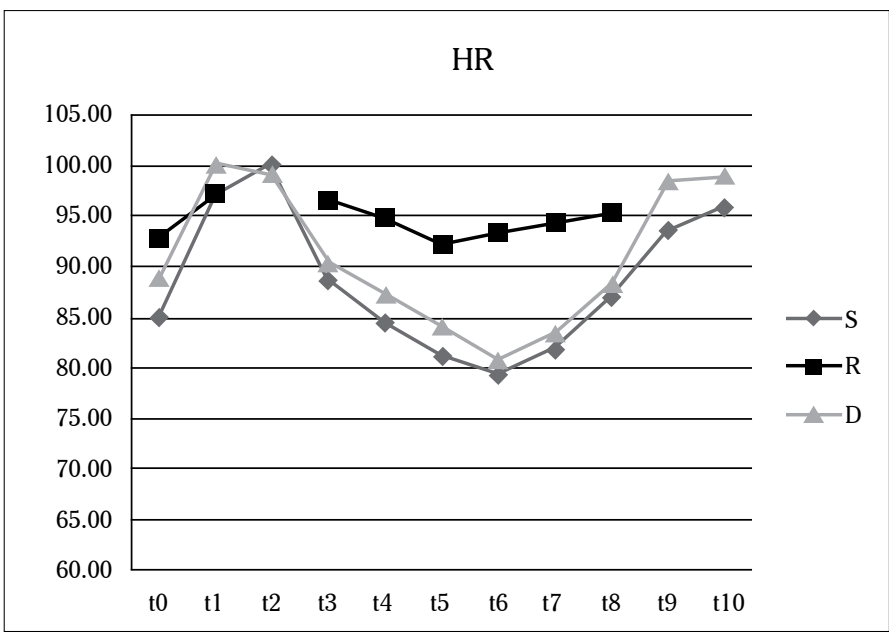

Figure 1. Heart rate (HR) of the patients (Mean \pm SD)

There was no statistically significant difference between postintubation BIS values of Groups S and D ( $>>0.05)$ (Figure 3$)$.

According to the $1^{\text {st }}$ minute Apgar scores of patients and times of birth, the $1^{\text {st }}$ minute Apgar score and time of birth (how many seconds after anesthesia induction) of patients in Group $\mathrm{R}$ were significantly higher than those of patients in Groups S and D

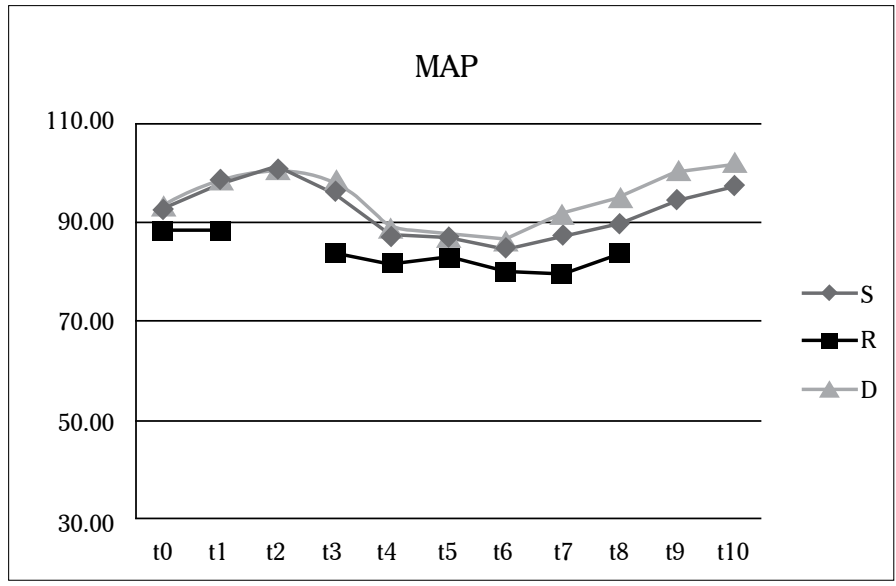

Figure 2. Mean arterial pressure (MAP) of the patients (Mean \pm SD)

Table 2. Characteristics of operation, APGAR Scores of newborns

\begin{tabular}{|c|c|c|c|}
\hline Groups & $\begin{array}{c}\text { Group S } \\
(n=25)\end{array}$ & $\begin{array}{c}\text { Group D } \\
(\mathrm{n}=25)\end{array}$ & $\begin{array}{c}\text { Group R } \\
(n=25)\end{array}$ \\
\hline Parity & $2.00 \pm 0.8$ & $1.60 \pm 0.76$ & $1.72 \pm 0.89$ \\
\hline Gestational Age (week) & $37.56 \pm 0.87$ & $37.44 \pm 0.87$ & $37.24 \pm 1.23$ \\
\hline APGAR $1^{\text {st }} \min$ & $7.24 \pm 0.61$ & $7.24 \pm 0.88^{\alpha}$ & $7.75 \pm 0.68^{* \alpha}$ \\
\hline APGAR $5^{\text {th }} \min$ & $8.80 \pm 0.53$ & $9.20 \pm 0.50$ & $9.00 \pm 0.41$ \\
\hline $\begin{array}{l}\text { Time of birth after } \\
\text { uterine incision (min) }\end{array}$ & $0.63 \pm 1.19$ & $0.65 \pm 0.20$ & $0.59 \pm 0.17$ \\
\hline $\begin{array}{l}\text { Time of birth after } \\
\text { anesthesia induction } \\
\text { (min) }\end{array}$ & $4.97 \pm 1.03$ & $5.24 \pm 1.08$ & $10.41 \pm 0.01^{\beta}$ \\
\hline \multicolumn{4}{|c|}{$\begin{array}{l}\text { Values are shown as Mean } \pm \text { SD. } \\
{ }^{\alpha} \mathrm{p}=0.034 \text { (Comparison between Group R and Group D) } \\
{ }^{\alpha} \mathrm{p}<0.01 \text { (Comparison between Group R and Group S) } \\
{ }^{\beta} \mathrm{p}<0.001 \text { (Comparison between Group S, Group D and Group R) }\end{array}$} \\
\hline
\end{tabular}

( $p=0.034, p<0.01$, respectively) (Table 2 ). There were no statistically significant difference in terms of age, parity, gestational week, $5^{\text {th }}$ minute Apgar score, and how many seconds after uterus incision time of birth is between the groups $S, R$, and D ( $>0.05)$ (Table 2). Total remifentanil dosage and Alderete $2^{\text {nd }}$ and $5^{\text {th }}$ minute scores were found to be significantly higher for patients in Group D than those of patients in Group S, and extubation time and eye opening times were found to be significantly higher for patients in Group $S$ than those of patients in Group D ( $<$ <.05) (Table 1).

There were no statistically significant differences among groups $\mathrm{S}, \mathrm{R}$, and $\mathrm{D}$ in terms of preoperative, postoperative $1^{\mathrm{st}}$ hour, postoperative $3^{\text {rd }}$ hour, and postoperative $1^{\text {st }}$ day MMSE and CDT values ( $p>0.05)$. In terms of TDT values, postoperative $3^{\text {rd }}$ hour and postoperative $1^{\text {st }}$ day TDT values were significantly different between Group $S$ and Group R patients, and postoperative $3^{\text {rd }}$ hour and $1^{\text {st }}$ day TDT values of patients in Group S were found to be significantly higher than those of patients in Group R $(p<0.05)$ (Table 3) (Figure 4-6). 
Table 3. Cognitive function tests of the patients

\begin{tabular}{|c|c|c|c|}
\hline Groups & $\begin{array}{c}\text { Group S } \\
(n=25)\end{array}$ & $\begin{array}{c}\text { Group D } \\
(n=25)\end{array}$ & $\begin{array}{c}\text { Group R } \\
(n=25)\end{array}$ \\
\hline \multicolumn{4}{|l|}{ MMSE } \\
\hline Preoperative & $24.72 \pm 2.34$ & $24.04 \pm 2.57$ & $23.88 \pm 2.91$ \\
\hline Postoperative $1^{\text {st }} \mathrm{hr}$ & $24.36 \pm 2.16$ & $24.12 \pm 2.76$ & $24.44 \pm 2.58$ \\
\hline Postoperative $3^{\text {rd }} \mathrm{hr}$ & $24.92 \pm 2.16$ & $24.80 \pm 2.72$ & $24.48 \pm 2.03$ \\
\hline Postoperative $1^{\text {st }}$ day & $25.00 \pm 2.10$ & $24.76 \pm 2.68$ & $24.60 \pm 2.32$ \\
\hline \multicolumn{4}{|l|}{ TDT } \\
\hline Preoperative & $4.60 \pm 2.71$ & $4.32 \pm 2.88$ & $3.96 \pm 2.78$ \\
\hline Postoperative $1^{\text {st }} \mathrm{hr}$ & $10.48 \pm 3.57$ & $10.24 \pm 4.02$ & $7.96 \pm 3.79$ \\
\hline Postoperative $3^{\text {rd }} \mathrm{hr}$ & $10.80 \pm 3.88$ & $8.12 \pm 4.80$ & $5.84 \pm 3.30^{*}$ \\
\hline Postoperative $1^{\text {st }}$ day & $9.04 \pm 4.16$ & $6.84 \pm 4.23$ & $5.40 \pm 3.18^{\alpha}$ \\
\hline \multicolumn{4}{|l|}{ CDT } \\
\hline Preoperative & $2.00 \pm 1.01$ & $2.24 \pm 1.05$ & $2.36 \pm 1.04$ \\
\hline Postoperative $1^{\text {st }} \mathrm{hr}$ & $1.32 \pm 0.85$ & $1.64 \pm 0.99$ & $1.68 \pm 0.95$ \\
\hline Postoperative $3^{\text {rd }} \mathrm{hr}$ & $1.72 \pm 0.89$ & $1.92 \pm 1.08$ & $2.12 \pm 1.01$ \\
\hline Postoperative $1^{\text {st }}$ day & $1.84 \pm 0.85$ & $1.92 \pm 1.08$ & $2.20 \pm 1.00$ \\
\hline \multicolumn{4}{|c|}{$\begin{array}{l}\text { MMSE: mini mental state examination test; TDT: trieger dot test; CDT: clock } \\
\text { drawing test } \\
\text { Values are shown as Mean } \pm \text { SD. } \\
\text { "p }<0.0001 \text { (Comparison between Group R and Group S) } \\
{ }^{\alpha} p=0.006 \text { (Comparison between Group R and Group S) }\end{array}$} \\
\hline
\end{tabular}

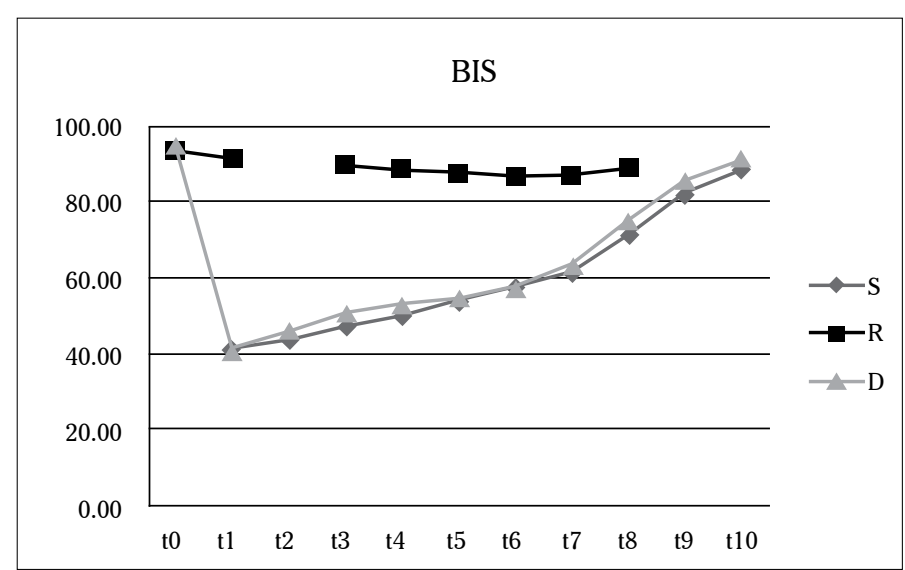

Figure 3. Bispectral index (BIS) values of the patients (Mean \pm SD)

\section{Discussion}

Although there are many studies evaluating the effect of anesthesia on POCD, the effect of anesthesia technique on POCD is unclear (9). In our study, we aimed to compare the effects of general anesthesia methods involving inhaled sevoflurane and desflurane agents and regional anesthesia applied via spinal anesthesia during elective cesarean operations on cognitive functions. In the literature, there is no study analyzing the relationship between anesthesia techniques applied during cesarean operations and early period POCD. Although it was found that

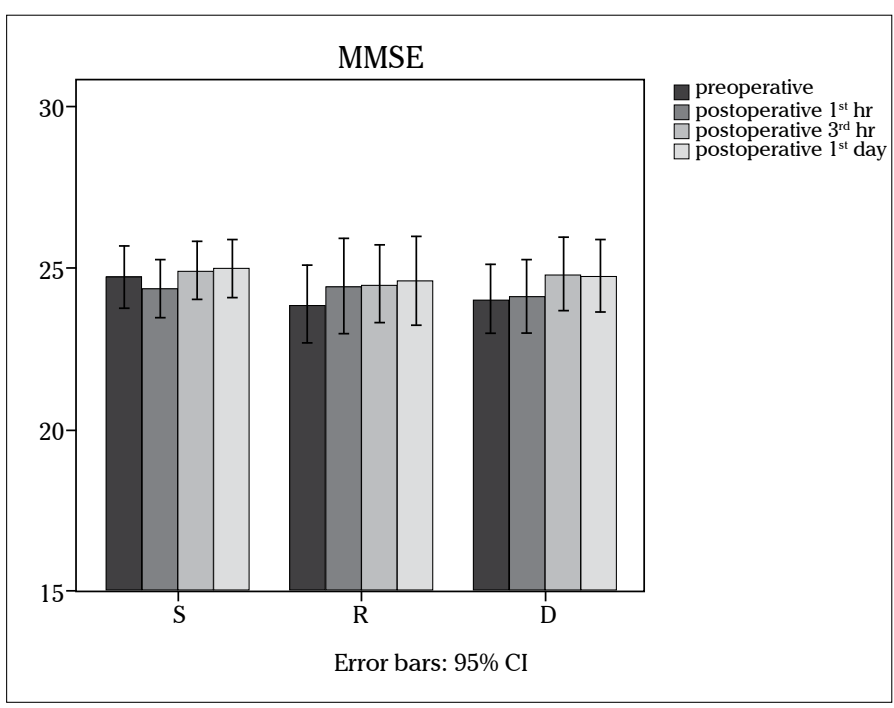

Figure 4. Mini-mental state examination (MMSE) of the patients (Mean \pm SD)

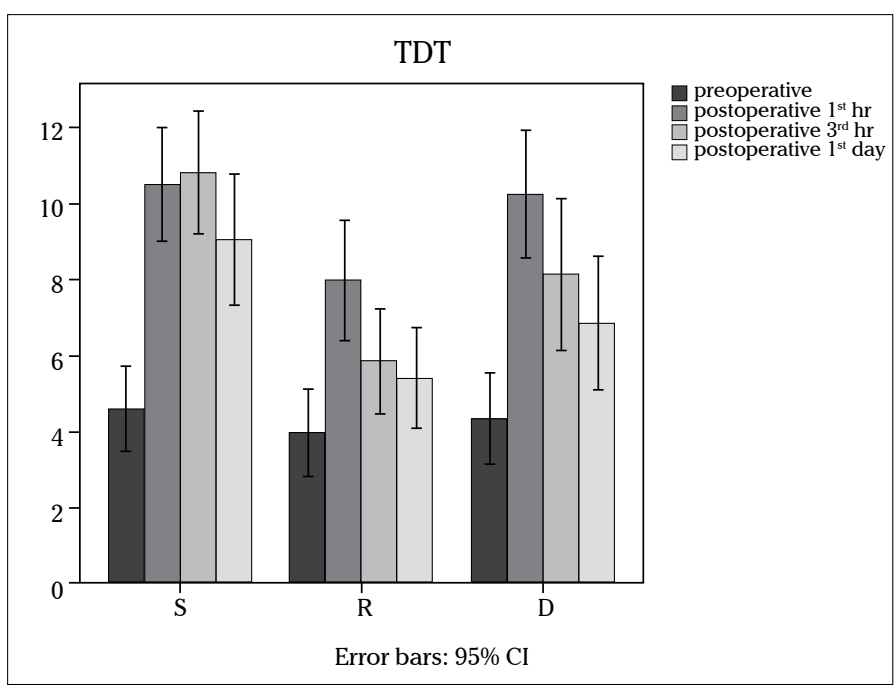

Figure 5. Trieger dot test (TDT) of the patients (Mean \pm SD)

general and spinal anesthesia have no negative effects on early period POCD, spinal anesthesia was found to be superior in the comparison between the groups that received general anesthesia with sevoflurane and regional anesthesia.

There are many studies suggesting that POCD may be prevented by performing regional anesthesia in suitable surgical operations, whereas some studies demonstrate that there is no significant difference between regional and general anesthesia with regard to POCD development $(9,11)$. Following cesarean operation, which is one of the obstetrical practices, POCD may theoretically develop, but a sufficient number of clinical studies evaluating the effect of anesthesia technique, psychological, nutritional, and stress status of mother on the incidence are required (12). We think that the occurrence of cognitive dysfunctions following cesarean operations performed under general anesthesia may be decreased using regional anesthesia more widely. Thus, both mother and baby can be protected from the possible harmful anesthetic effects of volatile and intravenous agents; unnecessary 


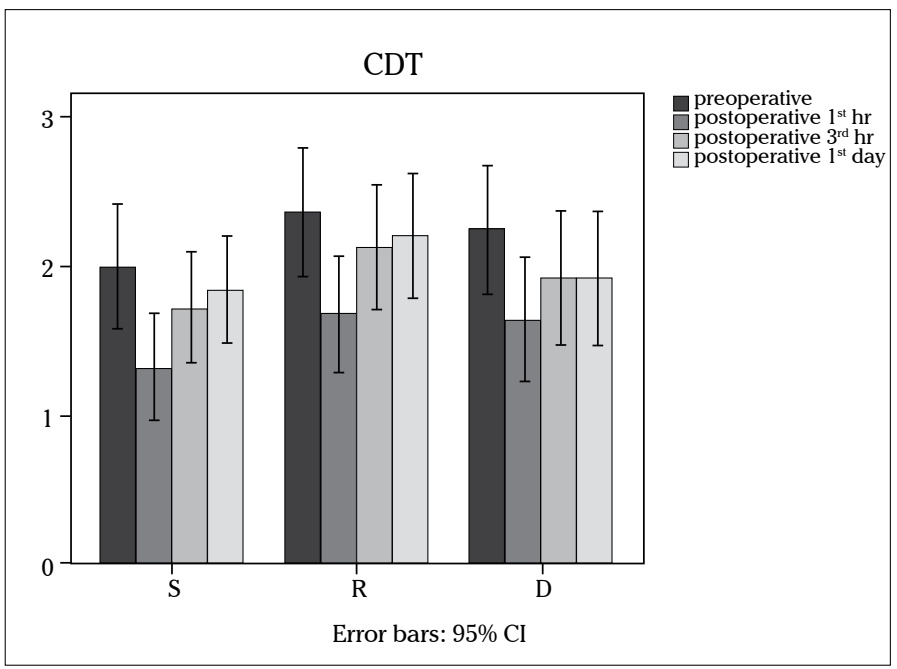

Figure 6. Clock drawing test (CDT) of the patients (Mean \pm SD)

separation of mother and baby is avoided by means of longer postoperative analgesia and absence of pain, somnolence, and malaise, which will be advantageous for patients.

Although there are many tests used to evaluate the cognitive functions, MMSE is widely used in studies because of its proven validity and safety in the Turkish population, applicability under both outpatient clinic and bedside conditions, and absence of uncomfortable and embarrassing aspects for the patient and physician. It is a 30-point test evaluating orientation, recording memory, attention and calculation, recall, and language $(2,13,14)$. MMSE score between 24 and 30 indicates intact cognitive functions, whereas scores 23 and below suggest impaired cognitive functions (13). In our study, we detected no difference between general and spinal anesthesia groups in terms of MMSE scores. It is known that all neuropsychological tests used in the evaluation of cognitive functions can be learned, which manifested itself as higher scores of memory (word tests) and mathematical thinking tests for some cases when compared with initial values. In addition to this, we believe that preoperative anxiety and depression may also be responsible for lower scores obtained at first evaluation. Larsen et al. (15) reported no difference between sevoflurane and desflurane groups in terms of postoperative TDT values. In the study by Chen et al. (16), it was reported that there was no significant difference between desflurane and sevoflurane groups with regard to MMSE values, and initial MMSE values were achieved by the end of the first postoperative day in all patients. In our study, we also found no difference between desflurane and sevoflurane groups and also between these groups and spinal anesthesia group with regard to MMSE.

In contrast to our study, Hole et al. (17) and Chung et al. (18) revealed that early postoperative cognitive dysfunction was more severe in the general anesthesia group when compared with the regional anesthesia group. Similarly, Papaioannou et al. (19) also reported that elderly patients who received general anesthesia demonstrated apparently more severe cognitive dysfunction. Williams- Russo et al. (20) suggested that the type of anesthesia did not affect the degree or mode of POCD in elective orthopedic surgery patients. Similarly, Berggren et al. (21) and Ghoneim et al. (22) suggested that general anesthesia and central block did not affect postoperative cognitive functions, whereas $\mathrm{Wu}$ et al. (23) reported that central block did not decrease POCD incidence when compared with general anesthesia. Tzabar et al. (6) declared that the incidence of cognitive dysfunction on postoperative $3^{\text {rd }}$ day following ambulatory surgery was apparently higher in the general anesthesia group when compared with the local anesthesia group.

We think that the type of anesthesia has no effect on POCD, particularly in short-time surgeries and young patients, but regional anesthesia may decrease the occurrence of known risk factors of POCD, such as respiratory complications, postoperative pain, and patient-originated results by contributing to intraoperative anesthesia and postoperative analgesia.

It is observed that the difference between the sevoflurane group and spinal anesthesia group in terms of TDT was significant, and TDT values of the sevoflurane group were significantly higher than those of the spinal anesthesia group. We believe that this result was achieved because pregnant women who received spinal anesthesia were more successful in the drawing TDT test because they were less sedated and more stable compared with the ones who received general anesthesia. Hence, it was found that the type of anesthesia had no effect on POCD, general anesthesia did not increase the development of early onset POCD measured by changes in MMSE scores, and regional anesthesia had no negative effects on cognitive functions when compared with general anesthesia.

Although sevoflurane does not cause tachycardia, high MAC value of desflurane or an acute increase in the inspired concentrations of desflurane causes tachycardia (24). Similar to the study of Nathanson et al. (25), our study also revealed that HR values were higher in the desflurane group when compared with the sevoflurane group, but this difference was insignificant. We think that this occurs because of the activation of sympathetic system caused by desflurane. Furthermore, we think that higher HR values of regional anesthesia group may be because of the anxiety caused by wakefulness of the patients receiving spinal anesthesia who are aware of all surgical procedure. It is also known that $\mathrm{SpO}_{2}$ value below $80 \%$ also causes impairment of cognitive functions (26). None of our cases involved in the study had hypoxia, which may be one of the possible positive effects on cognitive functions.

It is known that various inhaled anesthetic agents may cause different BIS values in patients even when they are applied in the same end-tidal concentrations providing the same potency (27). In their study, Farag et al. (28) revealed that the depth of anesthesia maintains continuity of cognitive functions during the postoperative period. They reported that patients with low intraoperative BIS values had less impairment in cognitive functions during postoperative 4-6 weeks. In the study by Zhang et al. (29), it was suggested that BIS values of the groups who received general anesthesia and those who received spinal anesthesia were similar, but because the degrees of cognitive function impairments were different, the depth of anesthesia may not affect POCD.

In our study, higher BIS values of the spinal anesthesia group compared with the general anesthesia group was an expected result, whereas extubation and post-extubation $5^{\text {th }}$-minute BIS values of the desflurane group were significantly higher than those of the 
sevoflurane group. We think that this is because of the rapid recovery related to low solubility of desflurane in blood and tissues. The limitation of this study includes the evaluation of cognitive functions in the early postoperative time period evaluated the POCD only early time period. It would be better if the cognitive tests were repeated in the first week and a month after the operation with a large number of patients.

In conclusion, this study reveals that general anesthesia with sevoflurane, general anesthesia with desflurane, and regional anesthesia via spinal injection had no deleterious effects on cognitive functions that were evaluated using MMSE, TDT, and CDT in patients undergoing cesarean operation. Therefore, we think that all three methods may be safely used in elective cesarean operations. We also think that further studies with a large number of patients evaluating the effects of general and regional anesthesia methods on cognitive functions in young and middle aged patients undergoing cesarean section and comparing different cognitive tests are required.

Ethics Committee Approval: Ethics committee approval was received for this study from Necmettin Erbakan University Ethical Committee.

Informed Consent: Written informed consent was obtained from patients who participated in this study.

Peer-review: Externally peer-reviewed.

Author Contributions: Concept - H.B., C.A.; Design - H.B., C.A.; Supervision - H.B.; Resource - H.B., C.A., O.S.; Materials - H.B., C.A., O.S.; Data Collection and/or Processing - C.A., O.S., K.G.; Analysis and/or Interpretation - H.B.; Literature Search - C.A., O.S.; Writing - C.A., H.B.; Critical Reviews - H.B.

Conflict of Interest: No conflict of interest was declared by the authors.

Financial Disclosure: The authors declared that this study has received no financial support.

\section{References}

1. Krenk L, RAsmussen LS, Kehlet H. New insights into the pathophysiology of postoperative cognitive dysfunction. Acta Anaesthesiol Scand 2010; 54: 951-6. [CrossRef]

2. Mehta Y, Singh R. Cognitive dysfunction after cardiac surgery. J Alzheimers Dis 2012; 22: 115-20.

3. Hope AT, Woolman PS, Gray WM, Asbury AJ, Millar K. A system for psycomotor evaluation design, implementation and practise effects in volunteers. Anesthesia 1998; 53: 545-50. [CrossRef]

4. Mashour GA, Forman SA, Campagna JA. Mechanisms of general anesthesia: from molecules to mind. Best Pract Res Clin Anaesthesiol 2005; 19: 349-64. [CrossRef]

5. Bryson GL, Wyand A. Evidence-based clinical update: General anesthesia and the risk of delirium and postoperative cognitive dysfunction. Can J Anesth 2006; 53: 669-77. [CrossRef]

6. Tzabar Y, Asbury AJ, Millar K. Cognitive failures after general anesthesia for day case surgery. Br J Anaesth 1996; 76: 194-7. [CrossRef]

7. Parikh SS, Chung F. Postoperative delirium in the eldery. Anesth Analg 1995; 80: 1223-32. [CrossRef]

8. Tsai SK, Lee C, Kwan WF, Chen BJ. Recovery of cognitive functions after anesthesia with desflurane or isoflurane and nitrous oxide. $\mathrm{Br}$ J Anaesth 1992; 69: 255-8. [CrossRef]
9. Rasmussen LS, Johnson T, Kuipers HM, Kristensen D, Siersma VD, Vila $\mathrm{P}$, et al. Does anaesthesia cause postoperative cognitive dysfunction? A randomised study of regional versus general anaesthesia in 438 elderly patients. Acta Anaesthesiol Scand 2003; 47: 260-6. [CrossRef]

10. Anwer HM, Swelem SE, el-Sheshai A, Moustafa AA. Postoperative cognitive dysfunction in adult and elderly patients--general anesthesia vs subarachnoid or epidural analgesia. Middle East J Anesthesiol 2006; 18: 1123-38.

11. Chung FF, Chung A, Meier RH, Lautenschlaeger E, Seyone C. Comparison of perioperative mental function after general anaesthesia and spinal anaesthesia with intravenous sedation. Can J Anaesth 1989; 36: 382-7. [CrossRef]

12. Ghosh S. The possibility of postoperative cognitive dysfunction in obstetric anaesthesia following caesarean section. Eur J Anaesthesiol 2012; 29: 61-3. [CrossRef]

13. Haase B. Cognition. In: Van Deusen J, Brunt D (editors). Assessment in Occupational Therapy and Physical Therapy. Philadelphia: W.B Saunders Company; 1997. p. 333-56.

14. Blake H, McKinney M, Treece K, Lee E, Lincoln NB. An evaluation of screening measures for cognitive impairment after stroke. Age Ageing 2002; 31: 451- 6. [CrossRef]

15. Larsen B, Seitz A, Larsen R. Recovery of cognitive function after remifentanil- propofol anesthesia: A comparison with desflurane and sevoflurane anesthesia. Anesth Analg 2000; 90: 168-74. [CrossRef]

16. Chen X, Zhao M, White PF, Li S, Tang J, Wender RH, et al. The recovery of cognitive function after general anesthesia in elderly patients a comparison of desflurane and sevoflurane. Anesth Analg 2001; 93: 1489-94. [CrossRef]

17. Hole A, Terjesen T, Breivik H. Epidural versus general anaesthesia for total hip arthroplasty inelderly patients. Acta Anaesthesiol Scand 1980; 24: 279-87. [CrossRef]

18. Chung F, Meier R, Lautenschlager E, Carmichael FJ, Chung A. General or spinal anaesthesia: wich is better in the elderly? Anesthesiology 1987; 67: 422-7. [CrossRef]

19. Papaioannou A, Fraidakis O, Michaloudis D, Balalis C, Askitopoulou $\mathrm{H}$. The impact of the type of anaesthesia on cognitive status and delirium during the first postoperative days in elderly patients. Eur J Anaesthesiol 2005; 22: 492-9. [CrossRef]

20. Williams-Russo WP, Sharrock NE, Mattis S, Szatrowski TP, Charlson ME. Cognitive effects after epidural vs general anesthesia in older adults. A randomized trial. JAMA 1995; 274: 44-50. [CrossRef]

21. Berggren D, Gustafson Y, Eriksson B, Bucht G, Hansson LI, Reiz S, Winblad B. Postoperative confusion after anaesthesia in elderly patients with femoral neck fractures. Anesth Analg 1987; 66: 497-504. [CrossRef]

22. Ghoneim MM, Hinrichs JV, O'Hara MW, Mehta MP, Pathak D, Kumar V, Clark CR. Comparison of psychologic and cognitive functions after general or regional anaesthesia. Anesthesiology 1988; 69: 507-15. [CrossRef]

23. Wu CL, Hsu W, Richman JM, Raja SN. Postoperative cognitive function as outcome of regional anesthesia and analgesia. Reg Anesth Pain Med 2004; 29: 257-68. [CrossRef]

24. Ebert TJ, Harkin CP, Muzi M. Cardiovascular responses to sevoflurane: a review. Anesth Analg 1995; 81: 11-2. [CrossRef]

25. Nathanson MH, Fredman B, Smith I, White PF. Sevoflurane versus desflurane for outpatient anesthesia: A comparison of maintenance and recovery profiles. Anesth Analg 1995; 81: 1186-90. [CrossRef]

26. An H, Liu Q, Chen Y, Lin W. Evaluation of MR-derived cerebral oxygen metabolic index in experimental hyperoxic hypercapnia, hypoxia and ischemia. Stroke 2009; 40: 2165-72. [CrossRef]

27. Samarkandi AH. The bispectral index system in pediatrics--is it related to the end-tidal concentration of inhalation anesthetics? Middle East J Anesthesiol 2006; 18: 769-78.

28. Farag E, Chelune GJ, Schubert A, Mascha EJ. Is depth of anesthesia, as assessed by the Bispectral Index, related to postoperative cognitive dysfunction and recovery? Anesth Analg 2006; 103: 633-40. [CrossRef]

29. Zhang B, Tian M, Zhen Y, Yue Y, Sherman J, Zheng H, et al. The effects of isoflurane and desflurane on cognitive function in humans. Anesth Analg 2012; 114: 410-5. [CrossRef] 